\title{
“UMA LIÇÃO DE AMOR”: O DIREITO À AUTONOMIA DAS PESSOAS COM DEFICIÊNCIA
}

"A LESSON IN LOVE": THE RIGHT TO AUTONOMY OF THE DISABLED

\author{
${ }^{1}$ Fernanda Holanda Fernandes
}

\section{RESUMO}

A Convenção Internacional sobre os Direitos das Pessoas com Deficiência tem como escopo a promoção da autonomia desses sujeitos e não apenas o tratamento médico ou assistencial. Nesse âmbito, assegura o direito à sexualidade, a um agrupamento familiar, ao reconhecimento legal, direitos civis e políticos, etc. Sob essa perspectiva, objetiva-se compreender a autonomia como elemento da dignidade da pessoa humana e os fundamentos teóricos do seu exercício pelas pessoas com deficiência. Para exemplificar, apresenta-se o filme "Uma lição de amor" sobre a história de um pai com retardo mental e sua luta judicial pela guarda da filha.

Palavras-chave: Pessoa com deficiência, Convenção internacional, Autonomia

\begin{abstract}
The International Convention on the Rights of Persons with Disabilities aims to promote the autonomy of these individuals. In this context, it guarantees the right to sexuality, family pool, legal recognition, civil and political rights, etc. From this perspective, the goal is to understand autonomy as an element of human dignity and the theoretical foundations of exercise for people with disabilities. As an example, presents the movie "I Am Sam" in the history of a parent with mental retardation and their legal battle for custody of their daughter.
\end{abstract}

Keywords: Person with a disability, International convention, Autonomy

\footnotetext{
${ }^{1}$ Bacharela em Direito pela Universidade Federal do Rio Grande do Norte - UFRN, Rio Grande do Norte (Brasil). E-mail: fernandaholanda.f@hotmail.com
} 


\section{INTRODUÇÃO}

Hodiernamente, se observa que os direitos das pessoas com deficiência (PCD) estão sendo defendidos pelas próprias pessoas com deficiência, que assumiram a luta pelo seu lugar no mundo. Contudo, nem sempre foi assim, por muito tempo esse segmento social estava restrito a ser objeto de legislações e políticas públicas que lhe diziam respeito, mas não atendiam as suas reais necessidades. Pois eram formuladas por terceiros que enxergavam a deficiência, mas não a vivenciavam e o resultado disso era a produção de políticas assistencialistas que ao invés de promover a autonomia dessas pessoas às tornavam mais dependentes e indefesas.

Nesse contexto, considera-se a elaboração da Convenção sobre os Direitos das Pessoas com Deficiência e seu Protocolo Facultativo, com vigência internacional a partir de $2008^{1}$, como o marco da mudança de paradigma na compreensão da deficiência. Pois elaborou uma nova definição sobre deficiência, baseada na substituição do modelo exclusivamente médico por uma visão multidisciplinar. Esta considera também os fatores psicossociais e tem como escopo promover, proteger e assegurar o exercício pleno e equitativo de todos os direitos humanos e liberdades fundamentais por todas as pessoas com deficiência (PCD).

Essa nova concepção possibilitou a Convenção reconhecer a autonomia e independência desses sujeitos, inclusive a liberdade para fazer as próprias escolhas. Ademais, o tratado determina como obrigação dos Estados-Partes adotar todas as medidas que viabilizem a autonomia e participação plena desses indivíduos na sociedade.

Dessa forma, a partir da CDPD a emancipação dessas pessoas passou a ser a tônica de qualquer normatização nesse campo. Entretanto, para tornar-se efetiva é preciso entender a natureza dessa autonomia, para traçar estratégias capazes de promover o seu exercício. E em face dessa problemática, se insere a questão: Quais os fundamentos teóricos que sustentam essa autonomia e de que modo ela pode ser exercida? Sob esse prisma, objetiva-se demonstrar como o modelo biopsicosocial da deficiência possibilita compreender esse grupo

\footnotetext{
${ }^{1}$ A CDPD foi adotada pela Assembleia Geral no dia 13 de dezembro de 2006, e aberta à assinatura dos Estadospartes em 30 de março de 2007. Eram necessárias vinte ratificações para que a CDPD ganhasse vigência e o último desses instrumentos foi entregue ao Secretariado da ONU em 3 de abril de 2008. Desse modo, ela entrou em vigência no dia 3 de maio de 2008 .
} 
de indivíduos como parte da diversidade humana e, portanto, sujeitos titulares do direito à autonomia, porém, uma autonomia com novas dimensões.

Para tanto, pretende-se abordar especificamente as diferenças entre o modelo exclusivamente médico de compreensão da deficiência e o modelo biopsicossocial; o conceito de autonomia como elemento da dignidade da pessoa humana e como essa concepção é abordada de forma equivocada pelo Direito; e as estratégias possíveis para o exercício da autonomia pelas pessoas com deficiência. Através dessa perspectiva, pretende-se demonstrar a hipótese de que a autonomia das pessoas com deficiência pode ser compreendida como uma construção interpessoal a partir dos conceitos de interdependência e apoio.

Em face da demanda de compreender como os novos conceitos introduzidos pela referida Convenção podem ser colocados em prática, empreendeu-se a análise do filme "Uma lição de amor", cujo enredo aborda a história de um pai diagnosticado com retardo mental, que luta na justiça para conseguir a guarda da filha. Dessa forma, a película explicita a condição de sujeito de direito das PCD, bem como as possibilidades encontradas pelo protagonista para atender às demandas sociais, exercendo a sua autonomia perante a lei e a sociedade.

Destaque-se que muitos trabalhos científicos se dedicam ao estudo da Convenção sobre os direitos das pessoas com deficiência, enfatizando a necessidade de superação do modelo de inclusão para o de emancipação. Porém, é imprescindível que pautando-se no princípio da igualdade material e no direito á diferença, se especifique a natureza dessa autonomia, tão almejada pelas novas políticas voltada a esse grupo. E nesse sentido, faz-se mister divulgar estudos que promovam a desmistificação do homem como um ser completamente independente e dotado de uma razão pura, para construir uma autonomia possível e concreta para os sujeitos com deficiência.

\section{O MODELO EMANCIPATÓRIO DE COMPREENSÃO DA DEFICIÊNCIA}

A Convenção sobre os Direitos das Pessoas com Deficiência e seu Protocolo Facultativo, vigentes no plano internacional a partir de $2008^{2}$, apresentam uma nova visão

\footnotetext{
${ }^{2}$ A CDPD foi adotada pela Assembleia Geral no dia 13 de dezembro de 2006, e aberta à assinatura dos Estadospartes em 30 de março de 2007. Eram necessárias vinte ratificações para que a CDPD ganhasse vigência e o último desses instrumentos foi entregue ao Secretariado da ONU em 3 de abril de 2008. Desse modo, ela entrou em vigência no dia 3 de maio de 2008.
} 
acerca do tratamento das pessoas com deficiência, sendo considerada como uma mudança de paradigma em relação à legislação anterior. ${ }^{3}$

A Convenção da Guatemala ${ }^{4}$ foi um precedente importante para a Convenção de Nova York, pois suas disposições já apontavam para uma nova perspectiva sobre a deficiência. Nesse cenário, o grande diferencial do tratado em estudo se deve ao fato da sua elaboração ter sido realizada com a participação das pessoas com deficiência. Assim, a Convenção de Nova York colocou em prática os princípios que iriam norteá-la durante o processo da sua própria formulação, concedendo às PCD autonomia para participar ativamente das políticas que lhe dizem respeito.

Dessa forma, considera-se que foi através dessa participação popular que surgiu o novo conceito de deficiência, apresentado no art. $1^{\circ}$ : "Pessoas com deficiência são aquelas que têm impedimentos de natureza física, intelectual ou sensorial, os quais, em interação com diversas barreiras, podem obstruir sua participação plena e efetiva na sociedade com as demais pessoas".

A transformação efetuada por essa concepção encontra-se no reconhecimento de que o meio ambiente socioeconômico pode ser causa ou fator de agravamento da deficiência, sendo esta considerada como o resultado da interação entre o indivíduo e o contexto em que vive. Substitui-se o modelo médico de compreensão da deficiência pelo modelo multidisciplinar que enfoca o sujeito na sua constituição biopsicossocial.

Nessa direção, é importante destacar as diferenças entre esses dois constructos teóricos. O paradigma médico enfatiza o tratamento da deficiência orientado para a cura, ou seja, busca-se a melhor adaptação possível da pessoa aos padrões sociais. Nesse caso, o problema da deficiência é situado dentro do indivíduo, e considerado como resultado exclusivo das limitações funcionais de origem biológica. Em contrapartida, o modelo social põe ênfase na reabilitação da sociedade, que deve ser concebida e desenhada para fazer frente às necessidades de todas as pessoas e não apenas daquelas que se enquadram nos seus parâmetros. (MALDONADO, 2013, p. 1100)

\footnotetext{
${ }^{3}$ A aprovação da CDPD no Brasil ocorreu pelo Congresso Nacional, via Decreto Legislativo n. 186, de 09 de julho de 2008, em dois turnos de votação, aprovado pelo voto de $3 / 5$ dos membros de cada Casa e a promulgação pelo Decreto n. 6949/2009.

${ }_{4}^{4}$ No âmbito regional, entrou em vigor, em 1999, a Convenção Interamericana para Eliminação de Todas as Formas de Discriminação Contra as Pessoas Portadoras de Deficiência - Convenção da Guatemala Aborda exclusivamente a proteção às Pessoas com Deficiência. Desataca-se que, desde o preâmbulo, apresenta as articulações entre deficiência e discriminação, demonstrando a relevância dos fatores socioeconômicos da deficiência, não se restringindo a considerações médicas. Promulgada, no Brasil, pelo Decreto n. 3956 de 8 de outubro de 2001 .
} 
O modelo social enfatiza a reabilitação da sociedade, que deve ser concebida para fazer frente às necessidades de todas as pessoas, integrando a diversidade inerente ao homem. Assim, este paradigma está centrado na dignidade da pessoa humana, situando o indivíduo no centro de todas as decisões que o afetam. E o mais importante, localiza o problema na sociedade e não no sujeito. (MALDONADO, 2013, p. 1100)

Nesse contexto, as limitações só se convertem em deficiência em razão da interação do indivíduo com um ambiente que não proporciona o apoio adequado para reduzir suas limitações. Nessa perspectiva, a deficiência deve ser entendida como um conceito fluído, um contínuo com graus de variação de acordo com as possibilidades do ambiente de oferecer o apoio necessário e potencializar as capacidades individuais (SCHALOCK, 2014, não paginado).

A partir dessas afirmações, pode-se acrescentar que, muitas vezes, a deficiência encontra-se no ambiente físico, social ou familiar em aceitar as diferenças individuais e se adaptar a elas. Pois a espécie humana tem como característica distintiva a diversidade, embora a ideologia dominante se esforce para disseminar a igualdade como uma forma de adequar os sujeitos à ordem social estabelecida.

Nesse âmbito, a definição sobre PCD, introduzida pela Convenção da ONU, é uma nova concepção acerca da deficiência, porque evidencia o "sujeito psicossocial", ao abandonar o conceito de deficiência como consequência natural de uma doença, incidindo sobre o organismo biológico do indivíduo. E passa a considerar a determinação ambiental, social e política da deficiência, deslocando a ênfase do sujeito para a relação entre ele e o meio social (BRASIL, 2009, p. 44). A partir dessa nova perspectiva, surge a ideia de que as limitações biológicas não devem ser traduzidas, na mesma proporção, em restrições sociais, pois aquelas são inatas, mas estas são impostas e transformam-se em obstáculo para qualquer tentativa de superação.

Destarte, emerge como direitos fundamentais das PCD não apenas acessibilidade aos locais, ao trabalho digno, à saúde, não discriminação, etc. Mas também, direitos que promovem a autonomia como a liberdade para fazer suas próprias escolhas, produzindo um novo modelo teórico sobre a deficiência, não mais restrito ao tratamento médico, mas voltado para promover a emancipação desses sujeitos. 


\subsection{PROMOÇÃO DA AUTONOMIA DAS PESSOAS COM DEFICIÊNCIA ATRAVÉS DA CONVENÇÃO DE NOVA YORK}

Buscando efetivar o modelo biopsicossocial sobre a deficiência, pautado na emancipação, a CDPD apresenta a autonomia como um dos princípios norteadores desse tratado, o art. $3^{\circ}$ elenca como princípios gerais da Convenção: autonomia, independência, liberdade de fazer as próprias escolhas; dignidade inerente à pessoa com deficiência; não discriminação; participação plena; respeito às capacidades das crianças com deficiência como pessoas em desenvolvimento.

Ademais, a autonomia das pessoas com deficiência vai sendo delineado, na referida Convenção, através de vários dispositivos que concedem direitos antes inimagináveis para pessoas com limitações funcionais. Um destes encontra-se no art. no art. $8^{\circ}$, b, que determina como obrigação dos Estados-Partes combater estereótipos, preconceitos inclusive aqueles relacionados ao sexo; garantir as pessoas com deficiência conservação da sua fertilidade (art. 23, c); oferecer às pessoas com deficiência programas e atenção à saúde, gratuitos ou a custos acessíveis, inclusive na área de saúde sexual e reprodutiva (art. 25, a).

A sexualidade, até aproximadamente 20 anos atrás, foi um tema esquecido nos estudos sobre deficiência. Salvo a abordagem da sexualidade das PCD como ameaça a outros pela suposta hipersexualidade ou como um perturbador atributo de pessoas percebidas como assexuadas; ou, ainda, enfocando a necessidade de proteção das PCD contra abuso ou exploração sexual. Não obstante, a evolução teórica do modelo médico para o modelo psicossocial, no plano dos estudos sobre a deficiência, teve reflexos no ativismo em prol dos direitos sexuais desses indivíduos. (SCHAAF, 2011, p.116)

Destaca-se a afirmação da Declaração Universal dos Direitos Humanos (1948) de que os direitos são universais, indissociáveis e interdependentes. Portanto, negar o direito à vida sexual implica em negar também a natureza humana dessa pessoa, e, consequentemente, todos os seus demais direitos. Contudo, ressalta-se a necessidade de se reconhecer as especificidades e garantir condições ou suportes indispensáveis para a vivência da sexualidade pelas PCD de maneira saudável. (BRASIL, 2009, p. 44)

Como decorrência do Direito a sexualidade, surge também a garantia para as PCD de poder constituir uma família, como postula o art. 23 sobre o direito de constituir, manter e planejar a família por pessoas com deficiência; preserva, também, o direito à filiação natural ou adotiva, bem como os cuidados inerentes à guarda aos pais com deficiência. 
Nesse diapasão, o direito a um agrupamento familiar emerge como um direito fundamental inerente à natureza do homem, que se constitui como um ser gregário movido pelas trocas afetivas. Dessa forma, observa-se que ao se considerar a deficiência como um conjunto de impedimentos que não afetam os atributos do sujeito, a deficiência não incapacita o indivíduo para as trocas de afeto. Assim, a constituição da família independe da capacidade civil, pois se deve distinguir a capacidade para a prática dos atos negociais do exercício dos atos exclusivamente existenciais. (FERRAZ, 2012, p. 328)

Observa-se que a CDPD prima não só pelo reconhecimento social das capacidades das pessoas com deficiência, mas também pelo reconhecimento legal, visto que o art. 12 discorre acerca do reconhecimento igual da capacidade jurídica para a fruição dos direitos, bem como para o exercício dos atos jurídicos por todas as pessoas com deficiência, inclusive mental ou sensorial, devendo ser respeitada a sua capacidade de decisão, garantindo-se a proteção por meio da tutela ou da curatela em caráter suplementar.

Dessa forma, cabe aos Estados-Partes tomar medidas para prover o apoio que necessitarem no exercício de sua capacidade legal. É dever dos Estados também assegurar que as medidas relativas ao exercício da capacidade legal respeitem a vontade e as preferências do indivíduo, e que tais medidas sejam condizentes com as circunstâncias individuais e se apliquem pelo período mais curto possível, sendo submetidas à revisão regular por uma autoridade ou órgão judiciário.

Nesse âmbito, destaca-se que não se trata de criar novos direitos para essas pessoas, mas sim garantir a elas o exercício de direitos considerados universais, inerentes ao ser humano. Por esse viés, o foco dessas garantias deve ser o sujeito e não a deficiência, pois esta é uma construção social e enquanto tal é passível de desconstruções e reconstruções.

Nessa esteira, o art. 26 prevê como dever dos Estados-membros promover as medidas apropriadas para possibilitar que as pessoas com deficiência conquistem e conservem o máximo de autonomia e plena capacidade física, mental, social e profissional, bem como plena inclusão e participação em todos os aspectos da vida. Isso deve ser feito através da organizarão, fortalecimento e ampliação dos serviços e programas completos de habilitação e reabilitação, particularmente, nas áreas de saúde, emprego, educação e serviços sociais.

É importante sublinhar que a autonomia não está restrita apenas á vida pessoal, essa se expande também para a participação política e social, contribuindo para o direito a cidadania das PCD. Nesse sentido, uma das grandes mudanças operadas pelo tratado em exame foi reconhecer um regime de direitos civis e políticos para esse segmento social. 
Observa-se que a ausência de tais direitos contribuiu, sobremaneira, para a abordagem assistencialista. Porquanto, os direitos sociais e econômicos são implementados progressivamente, sujeitos à disponibilidade dos recursos, esse caráter gradual os torna constantemente negociáveis. Enquanto os direitos civis e político por terem as características de disponibilidade imediata possuem uma aparência de não-negociáveis e permitem que seus detentores os afirmem sem ficar na defensiva ou envergonhar-se. Destarte, na ausência de um regime de direitos políticos e civis, as PCD não têm condições de reivindicar de forma assertiva seus direitos e precisam negociar continuamente pelas mesmas coisas. (DHANDA 2008, p. 46)

Como evidenciado, o tratado em estudo não se limita a declarar a autonomia como direito das pessoas com deficiência de forma genérica, ele especifica como esta pode ser alcançada e define os mecanismos para garantir o seu exercício. Elaborando, assim, o modelo emancipatório da deficiência. Para este não basta apenas incluir a pessoa com deficiência na sociedade, é necessário que ela possa participar da vida social da maneira que ela deseja e não através de formas pré-estabelecidas. Assim, não basta poder ir à escola, a PCD deve poder escolher a escola em que deseja estudar. Pois compreende-se a autonomia como a capacidade de escolher livremente as regras da própria vida e, nesse sentido, consiste em elemento essencial à dignidade da pessoa humana.

\section{AUTONOMIA COMO ELEMENTO DA DIGNIDADE DA PESSOA HUMANA}

É imprescindível sublinhar que a nova visão sobre deficiência, pautada no modelo biopsicosocial, possibilitou a mudança do paradigma assistencialista para o emancipatório, na medida em que reconhece os obstáculos do meio ambiente como fatores de limitação do desenvolvimento das pessoas com deficiência. Sob essa ótica, se estabelece a premissa de que havendo o aporte necessário e adequado, esses sujeitos podem ampliar suas potencialidades. Dentre estas, a autonomia está incluída, uma vez que ela é inerente a condição humana, não estando ausente nas pessoas com deficiência, mas apenas não estimulada. Nessa direção, considera-se a hipótese de que a autonomia é um elemento da dignidade da pessoa humana e, portanto, não pode ser negada a qualquer ser dessa espécie.

Nesse contexto, a autonomia pode ser definida como uma qualidade inerente ao ser humano, titular de um complexo de direitos asseguradores do não tratamento desumano ou degradante, bem como garantidor das condições existenciais mínimas para uma vida saudável, 
promovendo a participação ativa e corresponsável nos destinos da própria existência e da vida em sociedade. (SARLET, 2010, p. 70)

Dessa forma, considera-se que até mesmo os sujeitos com transtornos mentais devem ter mantida a sua autonomia, com o auxílio necessário. Porquanto, a capacidade de "desejar livremente" não está necessariamente atrelada á racionalidade enquanto percepção lógica.

A corroboração desse pensamento encontra respaldo na flexibilização da racionalidade como característica essencial do homem. Kant caracteriza a dignidade do através do seu valor absoluto que não comporta equivalente, ao contrário das coisas passíveis de substituição por um preço. Tal pensamento demonstra ser o homem o único animal capaz de dirigir suas ações em função de finalidades racionalmente percebidas e livremente desejadas e, portanto, não pode servir de meio para qualquer fim, pois ele é um fim em si mesmo. (COMPARATO, 2001, p. 72)

Porém, ressalta-se que essa racionalidade para autodeterminação das próprias ações deve ser entendida, sobretudo, no aspecto reflexivo. Visto que a singularidade eminente do ser humano é a aptidão para tomar a si mesmo como objeto da própria reflexão (COMPARATO, 2001, p.64). Essa capacidade se traduz na qualidade de autoconsciência, ou seja, consciência da própria subjetividade. E nesse ponto destaca-se a autonomia como produto dessa autoconsciência.

É importante acrescentar que mesmo nas pessoas com transtorno mental que podem ter uma percepção distorcida da realidade, esta percepção é objeto de uma autoreflexão, visto que o sujeito reage aos estímulos ambientais conforme seus pensamentos e sua consciência destes. Dessa forma, o ser humano se diferencia dos animais que agem em obediência cega aos ditames dos instintos, enquanto o homem é capaz de domar seus impulsos naturais e a eles sobrepor sua vontade, ainda que esta seja incompatível com os padrões sociais. Essa racionalidade mínima está presente em todo e qualquer ser humano, pois é uma qualidade inerente a essa espécie.

Essa capacidade para dirigir as próprias ações de acordo com os pensamentos não se confunde com a racionalidade lógica, pensamento compatível com os dados da realidade, que nas pessoas com transtorno mental pode está prejudicada. E, nesse caso, considerando a autonomia como "faculdade de escolher livremente os seus próprios fins, em razão da capacidade para apreciar valores - éticos, utilitários, estéticos, religiosos." (COMPARATO, 2001, p. 65) como seria possível para as pessoas que possuem alguma deficiência no pensamento racional exercer a autonomia? 
Nesse contexto, indica-se a impossibilidade de fundar uma ética em valores puramente formais e a necessidade de seus fundamentos serem percebidos em preferências axiológicas concretas, ditadas também pela emoção e pelo sentimento. (COMPARATO, 2001, p. 65).

Destarte, pode-se concluir que a autonomia não depende exclusivamente da racionalidade lógica para ser exercida, é possível uma relativização do aspecto racional, pois no homem não existe uma razão pura apartada dos demais elementos psíquicos. Em face dessas considerações é preciso promover uma ressignificação do conceito de sujeito do Direito, visto que esta se pauta exclusivamente na supremacia da razão.

É necessário que as ciências jurídicas relativizem a ideia de autonomia baseada apenas na razão consciente e considere a existência de um sujeito constituído socialmente. Nessa direção, alerta-se para o fato de que esse se encontra num processo dialético de transformar e ser transformado pela sociedade com suas instituições e normas. Destaca-se que tal concepção não representa uma apologia irracionalista, mas sim a possibilidade de uma significação dinâmica da razão através da percepção das suas múltiplas dimensões. (COSTA, 2008, p. 155)

Nessa direção, a autonomia deve ser compreendida a capacidade de autogoverno, de livre arbítrio quanto à regência de seu próprio destino, no fazer ou não fazer, no ir ou não ir, no aceitar ou no recusar e assim por diante, concedida pouco a pouco, por parâmetros biológicos e de convívio social, pois o uso da razão permite a percepção do outro como sujeito e diferencia os seres humanos dos animais, criando os contornos de sua personalidade. (COHEN e SALGADO, 2012, p. 227)

A partir desse panorama, se elabora a ideia de que a autonomia pode ser compreendida como uma construção interpessoal, na medida em que alguém só consegue exercitar o seu poder de fazer as próprias escolhas, a partir do reconhecimento da sociedade da sua capacidade e da oferta de oportunidades para que isso seja feito. Enquanto as PCD forem vistas como dependentes e não for concedido a elas espaço para falarem sobre si mesmas, sobre seus desejos, elas continuarão na posição de passividade, na qual amigos e parentes dirigem suas vidas.

Corroborando esse pensamento, a teoria do reconhecimento de Honneth compreende o indivíduo como dependente do reconhecimento intersubjetivo de suas capacidades e realizações. Quando a confirmação social não ocorre, em alguma fase do desenvolvimento, a consequência é o surgimento de uma lacuna psíquica na personalidade, na qual entram as reações emocionais negativas como vergonha e ira que se transformam em sintomas 
psíquicos, alimentados pela consciência de que lhe foi negado de forma injustificada o reconhecimento. (VICENZI, 2010, p.105)

Como evidenciado, o ser humano constrói a sua identidade através do discurso do outro, da maneira como a sociedade o enxerga. E nesse sentido, destaca-se a importância de enxergar a deficiência como parte da diversidade da espécie humana e considerar que as dificuldades biológicas podem ser superadas através da adaptação do ambiente físico e social. Pois, este último exerce um importante papel na constituição do sujeito, ao reconhecer suas necessidades e estimular o seu potencial. Assim, é a partir desses estímulos externos que a pessoa constrói a sua percepção sobre o mundo e sobre si mesma.

Dessa forma, compreende-se que não cabe ao Direito apenas tutelar a capacidade de discernimento das pessoas para a prática dos atos da vida civil, protegendo assim o seu patrimônio. É papel do Direito também proteger a liberdade individual, a capacidade do sujeito de refletir sobre si mesmo e construir a sua visão de mundo. Pois é através dessa faculdade que pode o sujeito completar o seu próprio direito e definir as suas pretensões jurídicas. Nesse âmbito, sublinha-se que o sujeito é por essência um ser "desejante" que está sempre em busca de algo, inclusive de se autodefinir. (VICENZI, 2010, p. 107)

Acrescente-se que nenhum ser humano consegue viver sem objetivos, por mais banais que possam parecer, é a capacidade para desejar que o mantém lutando pela sobrevivência. Assim, pode-se concluir que existe uma autonomia inerente ao ser humano, enquanto um ser eminentemente habitado por desejos e objetivos, que não pode ser retirada das pessoas com deficiência, sob pena de violar a sua dignidade.

\section{ANÁLISE DO FILME "UMA LIÇÃO DE AMOR"}

Embora a Convenção de Nova York (2008) assegure o direito à autonomia e especifique os diversos direitos dela decorrentes, surge á necessidade de compreender através de um caso concreto como os novos conceitos introduzidos pelo referido tratado podem ser colocados em prática. Em face disso, optou-se por analisar o filme "Uma lição de amor", por considerar que o cinema pode ser usado como um instrumento para lançar luzes sobre os conceitos jurídicos, contribuindo para a aprendizagem através do contato empático com os dramas humanos retratados.

Dessa forma, a película "Uma lição de amor" é ideal para a discussão acerca da autonomia das PCD, pois retrata a história de Sam, personagem vivido por Sean Penn, um 
homem diagnosticado com retardo mental, que ao ter uma relação sexual com uma jovem sem teto, a engravida. Esta, após o nascimento da filha, Lucy, abandona Sam deixando a menina aos seus cuidados. Contudo, quando Lucy completa 7 anos e começa a ultrapassar a idade intelectual do pai, a escola faz uma denúncia e uma assistente social é enviada à casa de Sam para verificar se ele tem condições de continuar com a guarda da garota.

Nesse contexto, o personagem e suas experiências são usados como referencial para abordar as dificuldades e possibilidade de uma pessoa com retardo mental se inserir no meio social e viver de forma autônoma. Evidencia-se o novo modelo biopsicossocial de conceituação do transtorno, que considera não apenas as causas biológicas da deficiência, mas também os fatores sociais e psicológicos.

A priori, é necessário destacar que Sam apresenta limitações cognitivas evidentes como dificuldades para desenvolver o pensamento abstrato; para se adaptar às novas situações; controlar suas emoções, etc. Contudo, apesar disso, ele consegue se inserir no meio social e viver com certa autonomia, mora sozinho, em seu apartamento, trabalha como garçom em uma lanchonete; possuí um grupo de amigos com os quais se reúne toda semana.

Diante desse panorama, suscita-se a questão acerca das possibilidades encontradas pelo sujeito para atender às demandas sociais, mesmo em face da deficiência e a importância dessas vias alternativas serem reconhecidas pelo sistema jurídico como legítimas para o exercício da autonomia.

Nesse contexto, ressalta-se que o retardo mental consiste numa condição clínica caracterizada por uma lentidão do desenvolvimento psíquico de um indivíduo, retardando o processo de desenvolvimento, amadurecimento e aprendizagem. O DSM-VI-TR (Manual diagnóstico e estatístico de transtornos mentais) reconhece o funcionamento intelectual significativamente abaixo da média como uma condição nuclear do retardo mental. E para efeitos de avaliação são destacados como elementos do diagnóstico a dificuldade de aprendizagem, a assimilação de informações novas e a condição de realizar abstração. (ABDALLA, 2004, p.319)

Sob esse prisma, é importante ressaltar que a deficiência não pode ser vista apenas como uma qualidade presente no organismo da pessoa ou no seu comportamento. Em vez de circunscrever a deficiência nos limites corporais da pessoa, como o fazem os manuais de psiquiatria, é necessário incluir as reações da sociedade como parte integrante e crucial do fenômeno, pois são essas reações que, em última instância, definem alguém como deficiente ou não deficiente. As reações apresentadas por pessoas diante das deficiências dependem 
bastante da interpretação que fazem, fundamentada em crenças científicas ou não (OMOTE, 1994, p. 68).

Assim, é imprescindível considerar a "construção social da deficiência", entendendo-se esta como o conjunto de expectativas dirigidas aos grupos e aos indivíduos com deficiência, expectativas estas que funcionarão como determinantes das interrelações estabelecidas com todos os elementos que constituem o grupo social. (SAETA, 1999, p. 52)

Trata-se, portanto, de contextualizar a deficiência mental na interação entre os fatores biológicos e sociais inerentes a constituição do ser humano. Nessa perspectiva, se o retardo mental é uma alteração na capacidade cognitiva do sujeito, esta mesma capacidade não se restringe a um atributo inato, ela também é desenvolvida a partir da interação com o ambiente externo.

É importante sublinhar que cognição e linguagem são socialmente formadas e culturalmente constituídas, nas relações concretas da vida. A linguagem, entendida como trabalho constitutivo exclui, de modo radical, a possibilidade de que o desenvolvimento cognitivo possa acontecer desvinculado da linguagem do Outro e dos signos; impossível pensar desenvolvimento cognitivo fora dos processos de significação que se criam entre as pessoas, no meio social (PADILHA, 2014, p. 15).

No filme, encontra-se elementos que concretizam essas concepções teóricas. Pois Sam encontra vias alternativas para responder às demandas sociais, servindo-se da linguagem cultural, para construir sua identidade enquanto sujeito. Uma vez que suas percepções e pensamentos possuem como referencial a banda inglesa "The Beatles". Desse modo, ele organiza a sua própria história através dos símbolos que fizeram parte da trajetória da banda, o maior exemplo disso é o nome da filha "Lucy" que faz referência a uma música que fala sobre "a menina dos olhos de caleidoscópio".

É fundamental o destaque a esse fato como indicador de uma possibilidade de desenvolvimento da capacidade cognitiva do sujeito, explicitando que o Coeficiente de Inteligência de Sam abaixo da média, não significa a sua incapacidade para encontrar um modo próprio de se inserir no contexto sociocultural que nos constitui como seres humanos.

Nesse sentido, entrar no mundo do simbólico, penetrar na cultura, significa inserir-se como sujeito da linguagem e supõem a entrada no mundo dos signos: dos gestos das palavras, das ações que possuem um significado. Ao compreender, dominar e criar sentidos, as pessoas desenvolvem as funções especificamente humanas: a vontade, a memória, a atenção 
voluntária, o raciocínio, o pensamento abstrato, a formação de conceitos, o afeto, a imaginação (PADILHA, 2014, p. 15).

Percebe-se que a construção da história pessoal a parti dos símbolos culturais, como constitutiva do próprio sujeito, é uma possibilidade viável para a superação dos limites impostos pela deficiência cognitiva. Assim, para enxergar na deficiência os caminhos possíveis de superação, é preciso compreender que muitas vezes o que é visto como uma inadaptação da pessoa, na realidade, é um modo diferente de funcionamento que busca minimizar os impactos das limitações biológicas.

Outra restrição advinda da deficiência mental, que impossibilitaria Sam de continuar com a guarda de Lucy, seria o fato dele possuir a idade mental de 7 anos, como poderia então educar uma criança que começa a ultrapassar a sua idade intelectual. De acordo com a teoria de Piaget, essa idade corresponde ao estágio das operações concretas. Este é vivenciado pela criança entre o sétimo e o décimo primeiros anos e caracteriza-se pela expansão da capacidade de distinguir aparência de realidade e características temporárias de permanentes. Alem disso, esboça-se uma tendência para resolver problemas por ensaio e erro, porém, persiste a dificuldade para lidar racionalmente com ideias abstratas (FIORELLI e RAZAZZONI 2009, p. 45).

Nessa esteira, é importante destacar a contribuição da Psicologia Jurídica em não se limitar aos dados teóricos, mas enquanto ciência empírica investigar a realidade na sua dimensão mais complexa. Pois, embora embotado intelectualmente, Sam possui uma percepção aguçada para os sentimentos. Ele percebe como a relação entre Rita (sua advogada) e seu filho é precária e a necessidade de diálogo entre os dois, aconselhando, inclusive, Rita a se separar do marido.

Em outros momentos, Sam demonstra a extrema sensibilidade e empatia que é capaz de ter pelos outros, como na situação em que Lucy vai apresentar um trabalho no colégio e esquece algo, ele dar-lhe apoio, comentando como realmente é difícil lembrar sobre aquela matéria. Em seu ambiente de trabalho, Sam conseguiu cativar os colegas e, em sua vida particular, vive rodeado de amigos.

Além disso, apesar de todas as suas limitações, Sam é capaz de mudar de residência para está mais próximo de Lucy, quando ela vai morar com a mãe substituta. E também se mostra apto a impor limites, quando todas as noites a menina pula pela janela para ir dormir na casa de Sam e ele a trás de volta à casa da mãe substituta e ainda lhe dar recomendações acerca de como fazer Lucy adormecer. 
O que antes parecia impossível para uma pessoa com "retardo mental" torna-se viável para Sam, a partir do momento em que ele compreende o quão importante para Lucy seria ter o amor de uma mãe. O que fica evidente é que a aprendizagem de Sam não é racional, mas pautada pelas emoções. E nesse contexto, cabe salientar as seguintes considerações:

\begin{abstract}
A emoção estabelece parâmetros dentro dos quais o exercício da razão pode ser realizado com êxito. O pensamento "racional" é extremamente limitado por motivos simples: As opções, para as mínimas coisas, são virtualmente infinitas; somente critérios emocionais permitem a tomada de decisão. A razão atua sobre o limitado leque de opções disponibilizado pela emoção. A emoção conduz literalmente o pensamento. Somente se consegue "ser racional" dentro de parâmetros emocionalmente aceitáveis. (FIORELLI e RAZAZZONI, 2009, p. 45)
\end{abstract}

Destaca-se que a emoção pode ser entendida como um complexo estado de sentimentos, com componentes somáticos, psíquicos e comportamentais, relacionados ao afeto e ao humor. Compreendendo-se afeto como a experiência da emoção observável que apresenta correspondentes nos comportamentos: gesticulação, voz etc; humor, bem-estar experimentado subjetivamente e possuindo intrínseca relação com a percepção de mundo do indivíduo. (FIORELLI e RAZAZZONI, p. 64)

Assim, embora o "retardo mental" seja definido como uma dificuldade na aprendizagem em razão do desenvolvimento intelectual abaixo da média. Como fícou demonstrado, não existe um único caminho para a aprendizagem. Nessa mesma perspectiva, destaca-se a inexistência, no âmbito da psicologia, de um conceito unívoco de inteligência, mas sim a presença de diversos conceitos, que, na verdade, focalizam aspectos diferentes dessa mesma função psíquica.

Nesse âmbito, evidencia-se as teorias que defendem a ideia da existência de diferentes tipos de inteligência geral, como é o caso da teoria de Thorndike, que sugere a classificação do comportamento inteligente em: inteligência mecânica, social e abstrata. (SPERLING, 1999, p. 82)

Nesse contexto, o diagnóstico de retardo mental baseando-se apenas no cociente intelectual não implica deficiência em outras áreas da vida social, como é o caso de Sam, que embora possua dificuldades no campo da abstração, possui habilidades sociais e emocionais. A teoria dos diferentes tipos de inteligência permite uma abordagem qualitativa do transtorno de retardo mental, ao reconhecer a existência de uma outra constituição psíquica, diferente do referencial que se tem como sinônimo de normal. 
Dessa forma, conclui-se que para além do modelo médico tradicional acerca da deficiência, vem se consolidando, a partir da Convenção sobre os direitos das pessoas com deficiência, o modelo biopsicossocial que aceita a existência de um leque de vias alternativas para que as pessoas com deficiência possam atender às demandas sociais de forma singular, sem serem consideradas inferiores ou menos capazes.

Nessa direção, o desfecho do filme vai ao encontro das ideias sobre autonomia aqui defendidas, ao sugerir a guarda compartilhada entre Sam e a mãe substituta, evidenciando o reconhecimento de que com a ajuda e o apoio necessário é possível para Sam desempenhar o seu papel de pai e que a autonomia não está baseada no paradigma da autossuficiência, mas sim na interdependência e apoio.

\section{CONCLUSÃO}

A partir do exposto, pode-se constatar que a Convenção sobre os Direitos das Pessoas com Deficiência representou a instituição de um novo paradigma no tratamento desses sujeitos, baseado na promoção da autonomia. Esta se torna possível na medida em que se passa a considerar os fatores sociais e psicológicos na determinação da deficiência, admitindo que existem alternativas para adaptar o ambiente e trabalhar as potencialidades das pessoas com deficiência para que os obstáculos e preconceitos sejam superados.

Entretanto, observa-se que o exercício da autonomia por essa parcela da população não se concretiza apenas através do sistema normativo, sendo necessário compreender suas premissas e o seu alcance. Nesse sentido, ressalta-se que para essa autonomia ser viável, é necessário a sua ressignificação pela sociedade e pelo Direito. A premissa fundamental a ser enfatizada é que embora existam vários graus de autonomia, existe uma parcela mínima desta presente em todo ser humano, pois diz respeito à capacidade de agir conforme os pensamentos e não apenas guiado pelos instintos.

Ademais, deve-se considerar que esse poder para autodeterminação não é sinônimo de autossuficiência, mas sim de uma construção interpessoal, pois através da relação com os outros, a pessoa com deficiência pode se constituir enquanto sujeito capaz de ter seus próprios objetivos, encontrando nessa interação o apoio necessário para fazer as próprias escolhas e o auxílio para executá-las.

Por fim, acrescente-se que a partir dessa nova visão acerca da deficiência é possível a implantação efetiva de um modelo capaz de promover a emancipação desses indivíduos e não 
somente a assistência médica ou social, visto que mais importante do que cuidar é preparar para a vida e ensinar a essas pessoas a cuidarem de si mesmas.

\section{REFERÊNCIAS}

ABDALLA, Elias. Retardo mental. In: Psiquiatria Forense. TABORDA, José; CHALUB, Miguel; ABDALLA, Elias 1.ed. Porto Alegre: Artmed, 2004. p. 315-326

BEATLES , The. Sgt. Pepper's Lonely Hearts Club Band. Inglaterra: EMI: 1967.8 disco compact ( $38+\mathrm{min})$ : digital, estéreo.

BRASIL. Decreto-Lei no 6.949, de 25 de agosto de 2009.Promulga a Convenção Internacional sobre os Direitos das Pessoas com Deficiência e seu Protocolo Facultativo. Disponível em: <http://www.planalto.gov.br/ccivil_03/_Ato2007 2010/2009/Decreto/D6949.htm>. Acesso em: 29 de maio. 2013.

BRASIL. Ministério da Saúde. Secretaria de Atenção à Saúde. Departamento de Ações Programáticas Estratégicas. Direitos sexuais e reprodutivos na integralidade da atenção à saúde de pessoas com deficiência. Brasília: Ministério da Saúde, 2009.

COHEN, Claudio; SALGADO, Maria Teresa Munhoz. Reflexão sobre a autonomia civil das pessoas portadoras de transtornos mentais. Revista Bioética, v. 17, n. 2, 2012. Disponível em:<http://revistabioetica.cfm.org.br/index.php/revista_bioetica/article/viewArticle/163>. Acesso em: 17 set. 2013.

COMPARATO, Fábio Konder. Fundamentos dos Direitos Humanos. Revista jurídica Consulex. Ano IV, v. I. n. 48, p. 52-61, 2001.

COSTA, Paulo Sérgio Weyl A. Para uma crítica à ideia de sujeito (do direito) contemporâneo. In: COSTA, Paulo Sérgio Weyl A. e. et al. Direitos humanos em concreto. Curitibá: Juruá, 2008.

DHANDA, Amita. Construindo um novo léxico dos direitos humanos: Convenção sobre os Direitos das Pessoas com Deficiências. Revista Internacional de Direitos Humanos, Ano 5, n. 8, jun. 2008. Disponível em: < http://www.conectas.org/Arquivos/edicao/pdfs/edicao201421014419117-56246426.pdf s> Acesso em: 25 mar. 2016.

FERRAZ, Carolina Valença. O direito das pessoas com deficiência nas relações familiares. In: FERRAZ, Carolina Valença. et al. (Coord).Manual dos Direitos das Pessoas com Deficiência. São Paulo: Saraiva, 2011. Cap. I, p. 19- 31

FIORELLI, José Osmir; RAZAZZONI, Rosana Cathya. Psicologia Jurídica. São Paulo: Atlas, 2009. 
MALDONADO, Jorge, A. Victoria. Hacia um modelo de atención a la discapacidad basado em los direchos humanos. Boletín Mexicano de derecho comparado, v.XLVI, n. 138, p. 1093-1109, 2013. Disponível em:

<http://www.juridicas.unam.mx/publica/librev/rev/boletin/cont/138/art/art8.pdf >Acesso em: 03 dez. 2013.

OMOTE, Sadao. Deficiência e não deficiência: recortes do mesmo tecido. Revista Brasileira de Educação Especial. v. 1, n.2. p. 65-73, 1994. Disponível em <

http://www.abpee.net/homepageabpee04_06/artigos_em_pdf/revista2numero1pdf/r2_art06.pd f> Acesso em 25 mar. 2016,

PADILHA, Anna Maria Lunardi. A Constituição do Sujeito Simbólico: para além dos limites impostos à deficiência mental. Pesquisa que resultou na tese de doutoramento, defendida em Março de 2000, na Unicamp. Disponível em:<

http://23reuniao.anped.org.br/textos/1523t.PDF>. Acessado em 26 de setembro, 2014.

SARLET, Ingo Wolfgang. Dignidade da pessoa humana e direitos fundamentais. 8 ed. Porto Alegre: Livraria do advogado, 2010

SCHAAF, Marta. Negociando Sexualidade na Convenção de Direitos das Pessoas com

Deficiência.Revista Internacional de Direitos Humanos. v. 8, n. 14, 2011. Semestral.

Disponível em:

<http://www.surjournal.org/conteudos/getArtigo14.php?artigo=14,artigo_06.htm>. Acesso em: 20 ago. 2013

SCHALOCK, Roberto, L. Hacia una nueva concepción de la Discapacidad. In: JORNADAS CIENTÍFICAS DE INVESTIGACIÓN SOBRE PERSONAS CON DISCAPACIDAD UNIVERSIDAD DE SALAMANCA, 3, 1999, Espanha. Disponível em: < http://campus.usal.es/ inico/investigacion/jornadas/jornada3/actas/conf6> Acesso em 24 de nov. 2013.

SAETA, Regina Beatriz. O Contexto Social e a Deficiência. Psicologia: Teoria e Prática, [S.I], v.1, n.1, p.51-55, 1999. Disponível em <

http://www.mackenzie.br/fileadmin/Editora/Revista_Psicologia/Teoria_e_Pratica_Volume_1_ __Numero_1/artigo7.PDF> Acesso em: 11 abr. 2013.

I am Sam (Uma lição de amor). Direção Jessie Nelson. Roteiro de Jessie Nelson e

KristineJohnsom. País/Ano de produção: EUA, 2001. Duração: 133mim. Gênero: Drama. DVD, son., color.Legendado.Port.

VICENZI, Brunela Vieira, de. Guinada Semântica: Indivíduo, Pessoa, Individualismo, Individualização e Sujeito de Direitos Fundamentais. In: NALINI, J. R. E CARLINI, A. (coord). Direitos humanos e formação jurídica. Rio de Janeiro: Editora Forense, 2010. 